\title{
Cellular Markers That Distinguish the Phases of Hemangioma during Infancy and Childhood
}

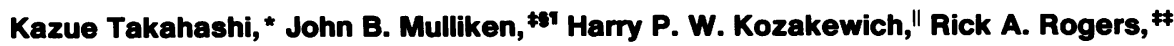 \\ Judah Folkman, ${ }^{\text {st** }}$ and R. Alan B. Ezekowitz* \\ ${ }^{*}$ Division of Hematology/Oncology, ${ }^{\ddagger}$ Division of Plastic Surgery, ${ }^{\S}$ Department of Surgery, and "Departments of Pathology and \\ Pediatrics, Children's Hospital, 'Departments of Surgery and **Anatomy and Cellular Biology, Harvard Medical School, and \\ ${ }^{\sharp}$ Department of Environmental Health, Harvard School of Public Health, Boston, Massachusetts 02115
}

\section{Abstract}

Hemangiomas, localized tumors of blood vessels, appear in $\sim 10-12 \%$ of Caucasian infants. These lesions are characterized by a rapid proliferation of capillaries for the first year (proliferating phase), followed by slow, inevitable, regression of the tumor over the ensuing 1-5 yr (involuting phase), and continual improvement until 6-12 yr of age (involuted phase). To delineate the clinically observed growth phases of hemangiomas at a cellular level, we undertook an immunohistochemical analysis using nine independent markers. The proliferating phase was defined by high expression of proliferating cell nuclear antigen, type IV collagenase, and vascular endothelial growth factor. Elevated expression of the tissue inhibitor of metalloproteinase, TIMP 1, an inhibitor of new blood vessel formation, was observed exclusively in the involuting phase. High expression of basic fibroblast growth factor (bFGF) and urokinase was present in the proliferating and involuting phases. There was coexpression of bFGF and endothelial phenotypic markers CD31 and von Willebrand factor in the proliferating phase. These results provide an objective basis for staging hemangiomas and may be used to evaluate pharmacological agents, such as corticosteroids and interferon alfa-2a, which accelerate regression of hemangiomas. By contrast, vascular malformations do not express proliferating cell nuclear antigen, vascular endothelial growth factor, bFGF, type IV collagenase, and urokinase. These data demonstrate immunohistochemical differences between proliferating hemangiomas and vascular malformations which reflect the biological distinctions between these vascular lesions. (J. Clin. Invest. 1994. 93:2357-2364.) Key words: hemangioma • angiogenesis $\bullet$ basic fibroblast growth factor $\bullet$ growth factors $\bullet$ tissue inhibitors of metalloproteinase

\section{Introduction}

Hemangioma is a benign vascular lesion and is the most common tumor of infancy. The incidence is $1-2 \%$ in neonates (1) and $12 \%$ by age 1 yr (2). Hemangioma occurs in $22.9 \%$ of premature infants with a birth weight below $1,000 \mathrm{~g}(3)$. Hemangiomas are more frequent in Caucasian infants than in other

Address correspondence to Dr. Kazue Takahashi, Enders 614, Children's Hospital, 300 Longwood Avenue, Boston, MA 02115.

Received for publication 3 September 1993 and in revised form 17 December 1993.

J. Clin. Invest.

(c) The American Society for Clinical Investigation, Inc.

$0021-9738 / 94 / 06 / 2357 / 08 \quad \$ 2.00$

Volume 93, June 1994, 2357-2364 racial groups. Female infants are more likely to develop hemangioma than males; the gender ratio is 3:1 (4). Most hemangiomas appear during the first weeks of life. The majority present as a single localized cutaneous tumor. However, hemangiomas may proliferate simultaneously in multiple sites anywhere in the body. Subcutaneous or visceral lesions may not manifest until the second to third month of life (5). The natural history of hemangiomas is characterized by rapid postnatal growth for 8-12 mo (the proliferating phase), followed by slow but inevitable regression for the next $1-5$ yr (the involuting phase) (5). There is complete regression of hemangiomas in over $50 \%$ of children by age $5 \mathrm{yr}$ and in over $70 \%$ by age $7 \mathrm{yr}$, with continued improvement in the remaining children until 10-12 yr (the involuted phase) $(1,4)$.

The majority of hemangiomas are minor vascular birthmarks that require no treatment. Approximately $10 \%$ of hemangiomas, however, become problematic, endangering or even life-threatening. Large lesions distort or ulcerate and destroy tissues (Fig. 1). Even a small hemangioma may interfere with function of a vital organ, e.g., obstruction of the airway or deformation of cornea resulting in loss of vision. Multiple lesions, particularly those in the liver, or large cutaneous lesions can divert considerable blood volume and produce high output heart failure. The extensive, possibly abnormal, endothelial surface within the tumor may induce platelet trapping and a thrombocytopenic coagulopathy (Kasabach-Merritt syndrome) (6).

The pathogenesis of hemangiomas is not well understood (5). The tumors are composed of microvessels lined by plump, mitotically active endothelial cells and pericytes $(5,7,8)$. The concept that tumors are "angiogenesis dependent," first proposed by Folkman, suggests new insights into the life cycle of hemangioma $(9,10)$. Angiogenic molecules are known to act on endothelial cells and pericytes to initiate the formation of capillary networks (11-17). This process is tightly regulated by inhibitors of endothelial cell growth which help to maintain the microvasculature in a quiescent state under physiological conditions $(17,18)$.

Thus, hemangioma offers a unique model to study angiogenesis as a primary tumor of microvasculature in which angiogenesis is initially excessive, followed by inhibition and regression of the newly formed blood vessels. Defining the growth phases of hemangioma requires clinical observation, and there is as yet no uniform standard for these stages. Some studies of hemangioma describe phenotypic endothelial cell and pericyte markers and demonstrate the presence of mast cells in histological sections $(5,19-27)$. There is no consensus, however, as to the state of differentiation of the cells or the presence of angiogenic molecules or their inhibitors. Vascular malformations do not exhibit increased endothelial cell turnover (7) nor do they contain elevated numbers of mast cells 

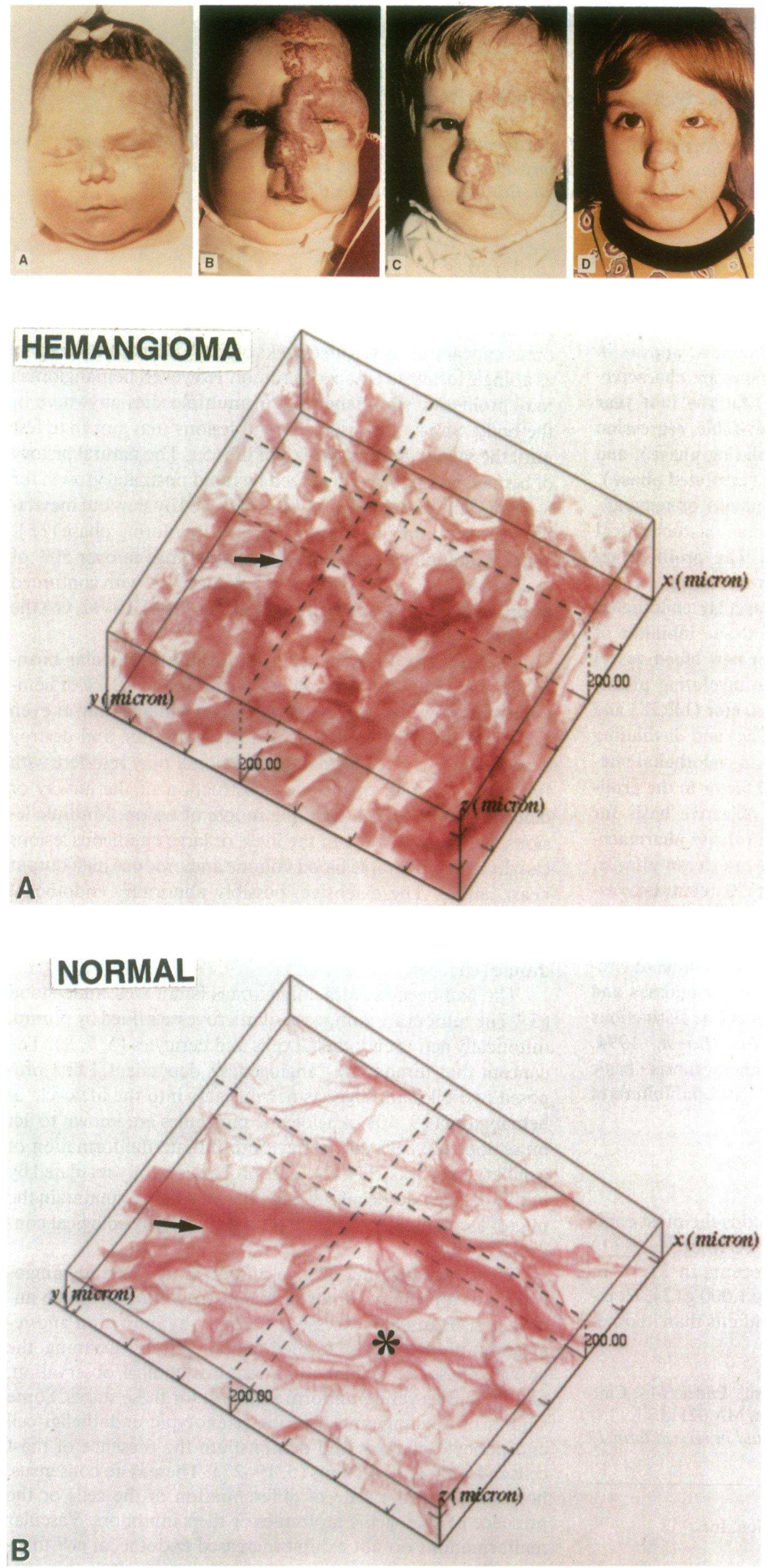

Figure 1. Clinical stages in the natural history of hemangioma. $(A)$ Apparently normal, newborn, female baby. Facial hemangioma rapidly evolved as seen in $B$, at 5 mo of age. At $3 \mathrm{yr}$ of age, the hemangioma is gradually regressing $(C)$, and by age 7 the child is undergoing surgical correction of the involuted tumor residuum $(D)$.
Figure 3. Three-dimensional reconstruction of optically sectioned skin from proliferating hemangioma $(A)$ and normal $(B)$ skin. $(A)$ The branching microvessels are arrowed. $(B)$ Blood vessels in normal skin are branched (arrow), but lack the tortuous nature of the vessel network as seen in $A$. Extracellular connective tissue elements $\left({ }^{*}\right)$ were verified under high magnification serial section analysis and appear as disjointed structures in this three-dimensional reconstitution. 
(22). We carried out an immunohistochemical study of a panel of antigens in an effort to define objectively the phenotype that could distinguish the proliferating, involuting, and involuted phases of hemangiomas, and vascular malformations. We analyzed the expression of proliferating cell nuclear antigen (PCNA) ${ }^{1}$ in histologic sections of surgical specimens. PCNA reflects the $S$ phase of the cell cycle (28). We also analyzed the angiogenic factors, vascular endothelial growth factor (VEGF) (14), and basic fibroblast growth factor (bFGF) (16, 17). Furthermore, we measured type IV collagenase, urokinase, and their inhibitors, i.e., tissue inhibitors of metalloproteinases (TIMP). We examined the expression of vWf, CD31, and $\alpha$-smooth muscle cell actin (SMC-actin). Mast cells were also counted. All of these analyses were carried out on tissue sections obtained at different stages of the life cycle of the hemangioma. We also examined a small series of vascular malformations, one specimen from each of the major single and combined channel abnormalities.

The rationale for analyzing collagenase, TIMP, and mast cells in these histologic specimens is $(a)$ extracellular proteolysis is a necessary step in capillary formation and angiogenesis and it may be regulated by the balance between proteolytic enzymes; $(b)$ recruitment of inflammatory cells has been reported in tumor-associated angiogenesis; and $(c)$ mast cells have been quantitated in late proliferating and involuting hemangiomas $(22,23)$. Furthermore, mast cell interactions with either fibroblasts or macrophages are observed in involuting lesions (24).

We show here that the three clinical stages of hemangiomas are clearly separable by specific histologic markers.

\section{Methods}

Specimens. 38 hemangioma specimens were obtained from tissue removed by surgical excision in infants and children ranging from $3 \mathrm{wk}$ to $15 \mathrm{yr}$ of age. None of the children had been treated with corticosteroids, interferon, or other pharmacological agents. All specimens were fixed in neutralized $4 \%$ formaldehyde, dehydrated through a graded series of ethyl alcohol to absolute xylene, and embedded in paraffin. Of 38 paraffin blocks, 20 specimens were processed in our laboratory, and 18 specimens were obtained from the Department of Pathology at Children's Hospital. Three phases in the natural history of hemangioma were clinically defined: $(1)$ the proliferating phase - the period of rapid growth, $0-12 \mathrm{mo}$; (2) the involuting phase-the period in which the lesion appears to slow its growth (proportionately to the growth of the child) and then regresses (usually by age 13-60 mo); and (3) the involuted phase-the period in which there is no further regression (after 61 mo). Vascular malformations were arterio-venous malformation, arterio-capillary-venous malformation, venous malformation, capillaryvenous malformation, and lymphatic malformation (lymphangioma). These patients were $8,18,11,14$, and 0.8 yr old, respectively.

Confocal microscopy. Paraffin blocks were sectioned at $500 \mu \mathrm{m}$ and deparaffinized with xylene followed by ethyl alcohol. Sections were stained fluorescently with Lucifer yellow $\mathrm{CH}(200 \mu \mathrm{g} / \mathrm{ml})$ (Molecular Probes, Inc., Eugene, OR) and embedded in Spurr plastic (Ernest F. Fullam, Inc., Latham, NY) as described previously (29). The embedded tissue was then examined at a magnification of 40 using a confocal laser scanning microscope (Sarastro 2000; Molecular Dynamics, Inc.,

1. Abbreviations used in this paper: $\mathrm{Ab}$, antibody; $\mathrm{bFGF}$, basic fibroblast growth factor; PCNA, proliferating cell nuclear antigen; SMC-actin, $\alpha$-smooth muscle cell actin; TBS, Tris-buffered saline; TIMP, tissue inhibitors of metalloproteinase; VEGF, vascular endothelial growth factor.
Sunnyvale, CA) fitted with a $25 \mathrm{~mW}$ argon-ion laser and an upright microscope (Optishot-2; Nikon Inc., Melville, NY). Serial optical sections $(0.5-\mu \mathrm{m}$ thick $)$ were collected at $0.5-\mu \mathrm{m}$ step intervals and rendered in three dimensions using Voxel View Ultra software (Vital Images, Inc., Fairfield, IA) to examine the three-dimensional nature and distribution of blood vessels within the specimens.

Antibodies. Antibodies (Abs) used for this study are summarized in Table I. Anti-human PCNA murine mAb, anti-human CD31 murine $\mathrm{mAb}$, and anti-human vWf murine $\mathrm{mAb}$ were purchased from Dako Corp. (Carpinteria, CA) (30-32). Anti-human bFGF murine mAb and the epitope peptide were gifts from Takeda Chemical Industry (Osaka, Japan) (Dr. K. Igarashi) (33). Anti-guinea pig VEGF rabbit $\mathrm{Ab}$ was generously provided by Dr. D. Senger (Beth Israel Hospital, Boston, MA) $(34,35)$. Anti-human type IV collagenase murine mAb was donated by Dr. W. G. Stetler-Stevenson (National Institutes of Health, Bethesda, MD) (36). Anti-human urokinase murine mAb was purchased from American Diagnostica Inc. (Greenwich, CT) (37). Anti-human TIMP rabbit Ab was a generous gift from Dr. $Z$. Werb (University of California, San Francisco, Berkeley, CA). AntiSMC-actin rabbit Ab was donated by Dr. I. Herman (Tufts Medical School, Boston, MA) (38). Alkaline phosphatase-conjugated goat anti-mouse or goat anti-rabbit $\mathrm{Ab}$ were purchased from Promega Corp. (Madison, WI).

Immunohistochemistry. Paraffin blocks were sectioned at 6-8 $\mu \mathrm{m}$ in thickness and attached to poly-L-lysine (Sigma Chemical Co., St. Louis, MO) coated glass slides. As an internal control, two to five sections from different specimens were attached to each slide. The paraffin sections were deparaffinized by xylene and gradual ethyl alcohol and then rehydrated in Tris-buffered saline (TBS), $\mathrm{pH}$ 7.4. All procedures were carried out at room temperature. The sections were incubated with protease $(250 \mu \mathrm{g} / \mathrm{ml})$ for $6 \min$ (type XXIV bacterium; Sigma Chemical Co.) before staining for CD31, vWf, bFGF, VEGF, and type IV collagenase. Sections were then incubated with blocking buffer (TBS supplemented with $2 \%$ goat serum and $0.05 \%$ Triton $\mathrm{X}-100$ ) for $10 \mathrm{~min}$.

Primary antibodies diluted with blocking buffers (Table I) were applied for $2 \mathrm{~h}$. After incubation with primary antibodies, alkaline phosphatase-conjugated goat anti-mouse IgG $(2.5 \mu \mathrm{g} / \mathrm{ml})$ or antirabbit $\operatorname{IgG}(2.0 \mu \mathrm{g} / \mathrm{ml})$ was diluted in blocking buffer or TBS alone for $2 \mathrm{~h}$. The immunoreactions were visualized as bright red precipitates by incubation with the substrate, fast red chromogen (Dako Corp.). The reaction was stopped by water and counterstained with hematoxylin, and the slides were mounted in water base mounting media. The opti-

Table I. Characteristics of Antigens and Antibodies, Including Concentrations or Dilutions Used in the Staining Procedure

\begin{tabular}{|c|c|c|c|}
\hline Marker & $\mathrm{Ab}$ & $\begin{array}{c}\text { Staining } \\
\text { concentration }\end{array}$ & $\begin{array}{c}\text { Molecular } \\
\text { mass }\end{array}$ \\
\hline & & & $k D$ \\
\hline PCNA & $\begin{array}{l}\text { Mouse mAb clone } \\
\text { PC10 }\end{array}$ & $5.8 \mu \mathrm{g} / \mathrm{ml}$ & 32 \\
\hline CD31 & $\begin{array}{l}\text { Mouse mAb clone } \\
\mathrm{JC} / 70 \mathrm{~A}\end{array}$ & $5.0 \mu \mathrm{g} / \mathrm{ml}$ & $120-130$ \\
\hline$v W f$ & $\begin{array}{l}\text { Mouse mAb clone } \\
\text { F8/86 }\end{array}$ & $1.6 \mu \mathrm{g} / \mathrm{ml}$ & $90-210$ \\
\hline bFGF & $\begin{array}{l}\text { Mouse mAb clone } \\
\text { M78 }\end{array}$ & $6.0 \mu \mathrm{g} / \mathrm{ml}$ & 18 \\
\hline VEGF & Rabbit Ab & Dilution at $1: 30$ & $34-42$ \\
\hline $\begin{array}{l}\text { Type IV } \\
\text { collagenase }\end{array}$ & Mouse mAb & $0.6 \mu \mathrm{g} / \mathrm{ml}$ & 72 \\
\hline Urokinase & Mouse mAb & $20 \mu \mathrm{g} / \mathrm{ml}$ & $33-50$ \\
\hline TIMP I & Rabbit Ab & Dilution at $1: 50$ & 31 \\
\hline SMC-actin & Rabbit Ab & Dilution at $1: 50$ & 40 \\
\hline
\end{tabular}



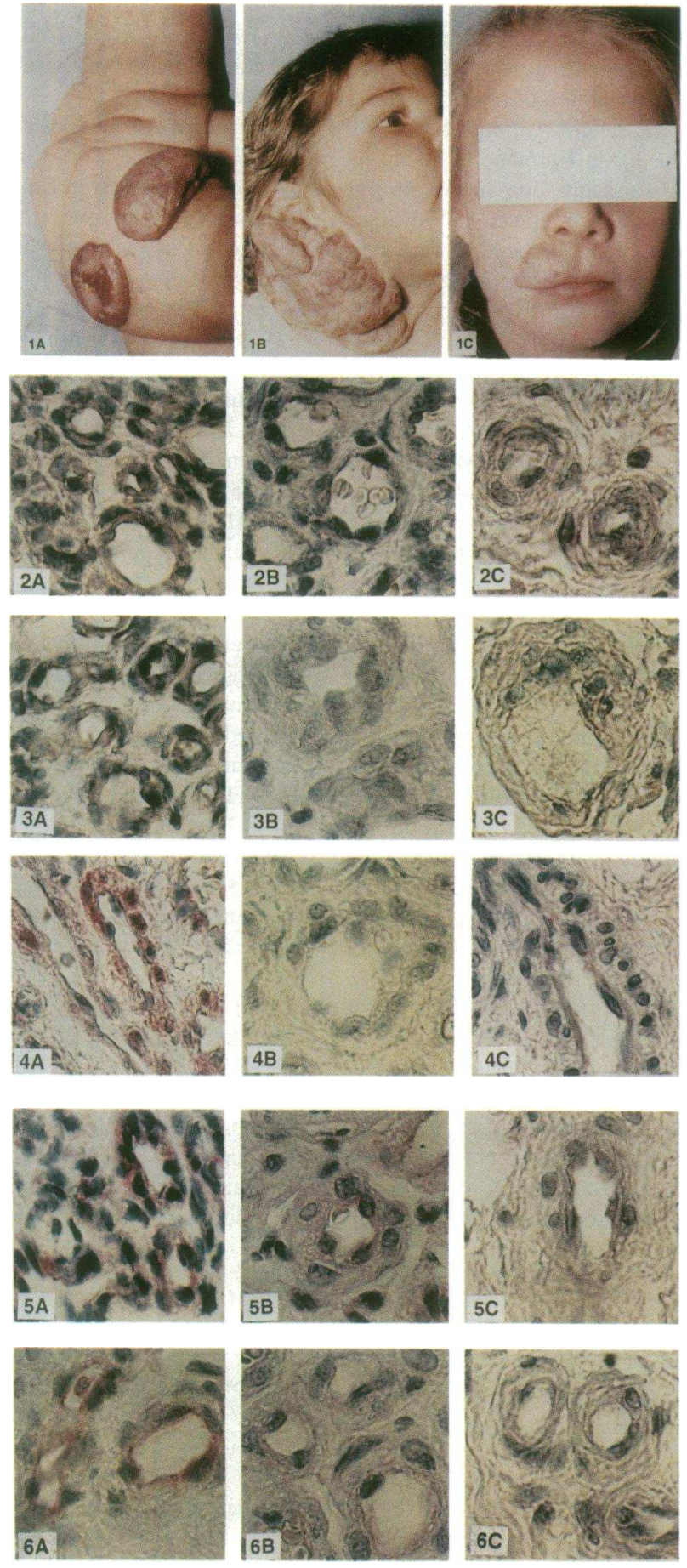
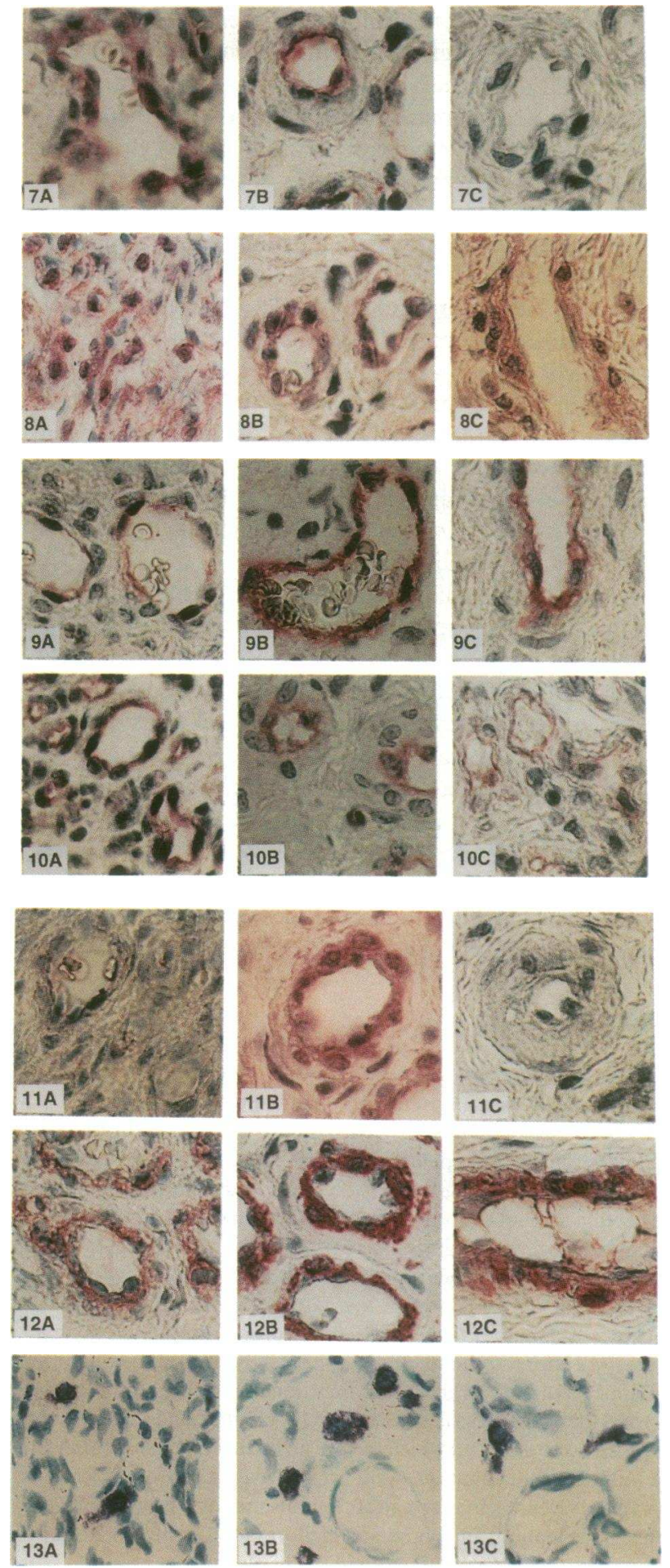

Figure 2. Immunostaining of the nine markers and mast cells in hemangioma's life cycle. $A$, Proliferating phase; $B$, involuting phase; and $C$, involuted phase. $(1 A-1 C)$ Representative specimens from each phase in the hemangioma cycle. Hemangioma in the proliferating phase is red and tense $(1 A)$. In the involuting phase, the skin becomes grayish, and the tumor is less tense $(1 B)$. In the involuted phase, redundant skin atrophies, and fibrous fatty tissue remains $(I C)$. From these three specimens, immunoreactivity for nine markers and mast cell staining is demonstrated $(\times 187)$. Negative control staining with goat anti-mouse IgG $(2 A-2 C)$ and goat anti-rabbit IgG $(3 A-3 C)$ showed no specific staining. Positive staining for the markers was visualized by alkaline phosphatase-dependent red staining against a blue nuclear counterstain, as described in Methods. PCNA staining was localized predominantly in the nuclei of pericytes of microvessels in $4 A$, but not in $4 B$ and $4 C$. VEGF staining was demonstrated in cytoplasm of both endothelial cells and pericytes of microvessels in $5 A$, but not in $5 B$ and $5 C$. Type IV collagenase staining was localized in the cytoplasm of endothelial cells lining microvessels in $6 A$, but not in $6 B$ and $6 C$. bFGF staining was observed in the cytoplasm of endothelial cells lining microvessels in $7 A$ and $7 B$, but not in $7 C$. Urokinase staining was seen predominantly in nuclei and cytoplasm of pericytes $(8 A-8 C)$. CD31 and vWf staining were localized in the cytoplasm of endothelial cells lining microvessels in $9 A-9 C$ and $10 A-10 C$, respectively. TIMP staining was observed in most pericytes and some endothelial cells in $11 B$, but not in $11 A$ and $11 C$. SMC-actin staining was localized in pericytes of microvessels in $12 A-12 C$. Mast cells were visualized as a pinkish purple hue in contrast with the other cell types, stained blue $(13 A-13 C)$. 
mal concentration of the primary and secondary antibodies was determined with several representative specimens before the staining experiments. These specimens were included as internal controls for each experiment. Control specimens that were not exposed to primary antibodies showed no specific red staining as seen in Fig. 2, $2 A-2 C$ (secondary goat anti-mouse $\mathrm{IgG}$ ) and $3 A-3 C$ (secondary goat anti-rabbit IgG). The results were scored by a modification of the method of Weidner et al. (39). Scoring was done on numbered specimens and without knowledge of the patient's name, diagnosis, age, or gender. The field with the greatest number of positive capillary-like vessels was noted at a magnification of 100 with light microscopy (MicrophotFXA; Nikon). In this area, the red stained vessels were counted as positive vessels per $0.78 \mathrm{~mm}^{2}$ at a magnification of 200 .

Staining of mast cells. Paraffin sections were deparaffinized, as described above, and then postfixed (methyl alcohol/chloroform/acetic acid, 6:3:1). These sections were incubated in toluidine blue solution for $2 \mathrm{~min}$. After rinsing with water and air drying, the sections were mounted in Permount (Fisher Scientific, Fair Lawn, NJ). Mast cells were identified by their pinkish purple hue which contrasted with the other cell types that stained blue. To score the results, the field with the greatest number of mast cells was found at a magnification of 100 and within this area the mast cells were counted as number per $0.25 \mathrm{~mm}^{2}$ at a magnification of 400 .

\section{Results}

Correlation of expression of PCNA, VEGF, and type IV collagenase with the proliferating phase of hemangioma. Antibodies to PCNA, VEGF, and type IV collagenase preferentially stained sections from hemangiomas in the proliferating phase. PCNA is a nuclear antigen expressed maximally in the $S$ phase of the cell cycle. Formation of tubes, branches, and capillary networks as demonstrated in the confocal image (Fig. 3) depends on division of pericytes and endothelial cells. Only rarely did these cells stain positively for PCNA in lesions defined as involuting or involuted phases. A representative specimen from each phase is shown in Fig. 2, 4A. The proliferating phase where PCNA staining localized in nuclei of pericytes and some endothelial cells is compared with nearly undetectable specific staining in sections from the involuting phase (Fig. 2, 4B) and the involuted phase (Fig. 2, 4C). The highest number of PCNA-stained microvessels was observed in the sections from proliferating lesions compared with sections taken in the other growth phases. There were statistically significant differences among the three phases of hemangioma (Fig. 4). Staining for VEGF (a specific mitogen for endothelial cells) was localized predominantly within the cytoplasm of pericytes and endothelial cells of the microvessels during the proliferating phase (Fig. $2,5 A)$. No immunoreaction was observed in sections from the involuting or involuted phases (Fig. $2,5 B$ or $5 C$ ). Overall ANOVA for these markers between the three groups indicated that the difference was significant (Fig. 4). A similar staining pattern to that observed for PCNA and VEGF was seen when type IV collagenase staining was analyzed for all samples from the three groups (Fig. 2, 6A-6C and Fig. 4). Staining of metalloproteinase, a type IV collagenase, was localized in proliferating phase lesions as seen in a representative section (Fig. 2, 6A).

bFGF (an angiogenic polypeptide) staining was observed within the cytoplasm of endothelial cells lining microvessels in both the proliferating and involuting phases (Fig. 2, 7A and $7 B$ ), but not in sections from involuted tissue (Fig. 2, 7C). The expression of bFGF was significantly higher in the proliferating phase as compared with the involuted phase (Fig. 4).

Urokinase, CD31, and vWf failed to discriminate between proliferation and involution, as abundant staining was observed in sections from both of these phases in the hemangioma. Urokinase staining was localized in the nuclei and cytoplasm of pericytes and endothelial cells in sections from all phases (Fig. 2, 8A-8C). The expression of urokinase was significantly higher in both proliferating and involuting phases than in the involuted phase $(P<0.05, t$ test $) . C D 31$ and vWf were localized in endothelial cytoplasm in microvessels in sections from all three phases (Fig. 2, 9A-9C and $10 A-10 C$ ). The expression of CD31 was significantly higher in the involuting phase than in the involuted phase (Fig. $4, P<0.05$ ). The expression of vWF was significantly higher in the combined proliferating and involuting phases than in the involuted phase ( $P$ $<0.05, t$ test $)$.

Correlation of expression of TIMP, SMC-actin, and mast cells with the involuting phase of hemangioma. Proteases and their inhibitors may be considered as indirect regulators of angiogenesis. Type IV collagenase and urokinase are associated with angiogenesis while TIMPs are reported to be inhibitors of
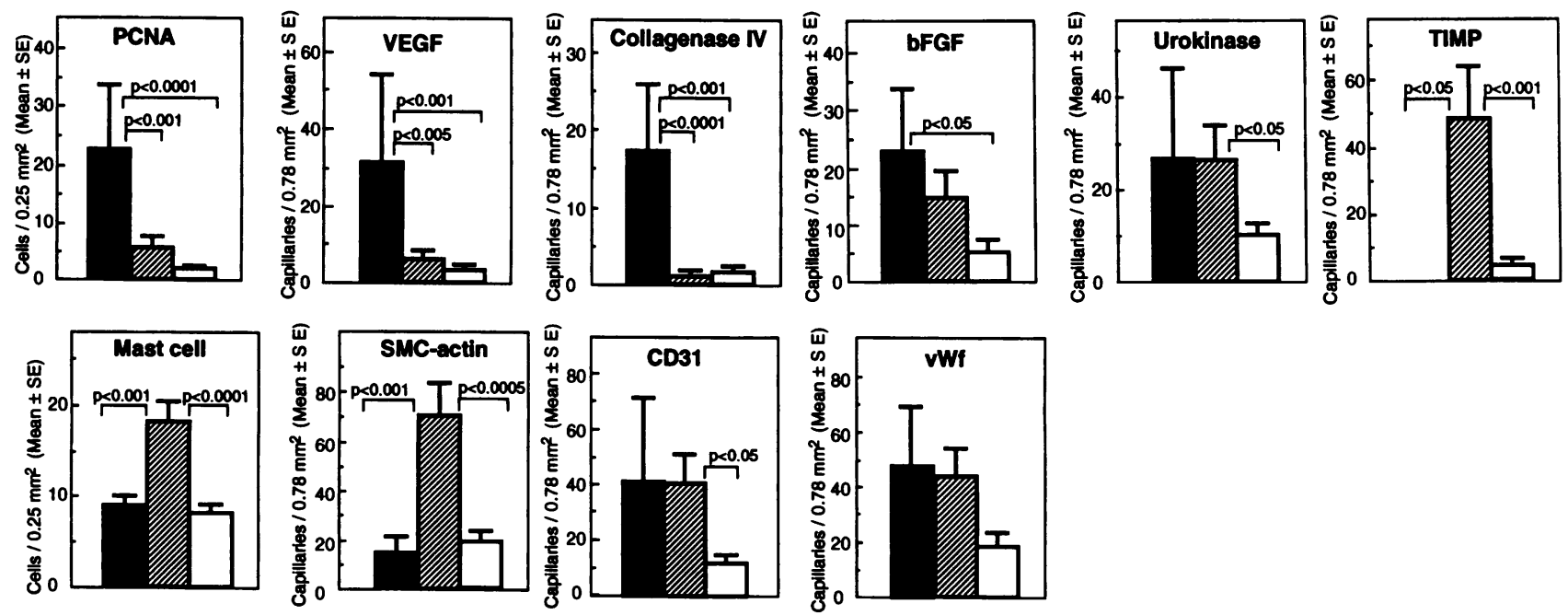

Figure 4. Immunoreactivity of nine markers and mast cells in the three growth phases of hemangiomas. Immunostaining of nine markers and mast cell was scored to assess significance between three groups, proliferating phase (0-12 mo) ( 0 ), involuting phase (13-60 mo) ( $\square)$, and involuted phase (61-180 mo) (ם). For each group in each marker, mean \pm SE was plotted. The results were subjected to overall ANOVA, and the significant differences among these three groups were assessed by Fisher Protected Least Significant Difference test and reported as $P$ values. 
neovascularization. Thus, it is interesting that TIMP 1 expression was not observed in sections from the proliferating phase, but was readily detectable in sections from the involuting phase. Furthermore, TIMP 1 staining was localized predominantly in pericyte cytoplasm of microvessels in the involuting phase (Fig. 2, $11 B$ ), but not in those from the proliferating or involuted phases (Fig. 2, $11 \mathrm{~A}$ or $11 \mathrm{C}$ ). Finally, the expression of TIMP was significantly higher in the involuting phase than in either the proliferating or involuted phases (Fig. 4). SMCactin, a marker of mature smooth muscle cells, was more prominent in involuting phase lesions than in sections from the proliferating and involuted phases. The staining was localized in the cytoplasm of pericytes in sections from all phases (Fig. 2, $12 A-12 C$ ) as well as smooth muscle cells (data not shown). Analysis of specimens from all three groups revealed that the expression of SMC-actin was significantly higher in the involuting phase than in both the proliferating and involuted phases (Fig. 4).

Mast cells stained by toluidine blue predominated in the early to middle involuting phase, but only scattered mast cells were observed as lesions matured (Fig. 2, 13A-13C). The presence of mast cells was significantly greater in the involuting phase than in either the proliferating or involuted phases (Fig. 4).

Low expression of nine markers and mast cells in vascular malformations. The microvessels of various types of vascular malformations showed little or no immunoreactivity with all nine markers, as seen in Table II. The expression of these markers was in a range observed in the involuted phase of hemangiomas (Fig. 4). As expected, vWf staining was observed in sections from all the classes of vascular malformation examined. Other blood vessel markers, CD31 and SMC-actin, were also detected in all lesions, except venous malformation appeared not to express the CD31 antigen. Collagenase IV staining was not detected in any of the vascular malformations. Barely detectable bFGF, PCNA, VEGF, and urokinase staining were observed in cytoplasm of pericytes as well as endothelial cells of microvessels in some sections (Table II). Occa-

Table II. Immunoreactivity of Nine Markers and Mast Cells in Individual but Representative Various Vascular Malformations

\begin{tabular}{lrrrrr}
\hline & \multicolumn{5}{c}{ Vascular malformations } \\
\cline { 2 - 6 } \multicolumn{1}{c}{ Markers } & VM & AVM & CVM & ACVM & LM \\
\hline PCNA $^{*}$ & 1 & 4 & 4 & 1 & 0 \\
VEGF $^{\ddagger}$ & 4 & 0 & 0 & 0 & 0 \\
Collagenase IV $^{\ddagger}$ & 0 & 0 & 0 & 0 & 0 \\
bFGF $^{\ddagger}$ & 6 & 4 & 0 & 0 & 2 \\
Urokinase $^{\ddagger}$ & 6 & 0 & 0 & 3 & 0 \\
TIMP $^{\ddagger}$ & 3 & 13 & 4 & 1 & 0 \\
Mast cell* $_{\text {SMC-actin }}^{\ddagger}$ & 10 & 4 & 5 & 4 & 14 \\
CD31 $^{\ddagger}$ & 10 & 13 & 24 & 7 & 20 \\
vWf $^{\ddagger}$ & 0 & 18 & 3 & 2 & 19 \\
& 8 & 3 & 12 & 4 & 14 \\
\hline
\end{tabular}

Immunostaining of nine markers and mast cell was scored as described in Methods. $A V M$, arterio-venous malformation; $A C V M$, arterio-capillary-venous malformation; $V M$, venous malformation; $C V M$, capillary-venous malformation; and $L M$, lymphatic malformation. * Positive cells per $0.25 \mathrm{~mm}^{2}(\times 400) ;{ }^{\ddagger}$ positive vessels per $0.78 \mathrm{~mm}^{2}(\times 200)$. sional mast cells were observed at a similar frequency to the involuted phase of hemangiomas (Table II and Fig. 4).

Confocal imaging of capillary networks in a proliferating phase hemangioma. Three-dimensional images of a proliferating hemangioma and normal skin were reconstructed by confocal microscopy (Fig. 3). Optical sections rendered in three dimensions were collected from the tissue block and revealed a tortuous network of disorganized microvessels (Fig. $3 \mathrm{~A}$ ). The sections showed crowding of new microvessels and sprouts. In contrast, microvessels in normal skin were sparse and uniform (Fig. 3 B).

\section{Discussion}

Characterizing the life cycle of hemangioma into three phases is based solely on clinical observation. The proliferating phase, spanning the first 12 mo of age, is followed by the involuting phase (12-60 mo), and the tumor is finally involuted by $12 \mathrm{yr}$ of age (5). Although these clinical phases are useful in assessing the longitudinal changes in individual lesions, there is no standardization to permit accurate comparison between patients. This is essential to assess the efficacy of treatments directed at accelerating regression of hemangiomas.

We examined the expression of a panel of nine markers in a cohort of specimens from patients whose lesions had been staged clinically. Our goals were to document the three phases at the cellular level and to gain insight into the pathogenesis of hemangioma. We found that the expression of PCNA, VEGF, and type IV collagenase as well as the absence of TIMP I distinguished proliferating phase lesions from the subsequent phases (Fig. 4). In contrast, the involuting phase was characterized by prominent expression of TIMP I with correspondingly less expression of PCNA, VEGF, and type IV collagenase. VEGF has been implicated in angiogenesis because it specifically induces proliferation of endothelial cells and also results in increased vascular permeability $(14,15,40-42)$. Conspicuous expression of VEGF during the proliferating phase of hemangioma provides circumstantial evidence that this peptide may be involved in the pathogenesis of the tumor along with bFGF, another angiogenic peptide.

Interestingly, bFGF was expressed prominently throughout the first two growth phases, but was undetectable in the terminal phase of the cycle. bFGF staining was localized in the cytosol of endothelial cells, as described previously $(43,44)$, but was not detectable in the basement membrane as has been documented in other organs, such as the cornea and the gastric mucous (45-47). Recently, we have demonstrated high levels of bFGF in the urine of infants and children with hemangiomas (Folkman, J., T. Law, S. Connors, J. Mulliken, D. MacDonald, and R. A. B. Ezekowitz, unpublished observation). The lack of detectable bFGF in the extracellular matrix could possibly result from its mobilization by collagenase, which is coexpressed (45). It is also possible that bFGF in the extracellular matrix of hemangioma is below the sensitivity of the assay.

The pattern of bFGF staining was mirrored in the endothelial cell phenotypic markers, CD31 and vWf. Absent or low level staining was observed in early lesions or lesions in the late involuted phase. These specimens were at the extremes of the spectrum of the hemangioma growth cycle. These findings suggest a progression from endothelial immaturity to maturity (CD31, vWf positive) and ultimate senescence, wherein cells are no longer capable of expressing the endothelial phenotype. In addition, SMC-actin expression was localized to pericytes in 


\section{Status in the life cycle of hemangioma}

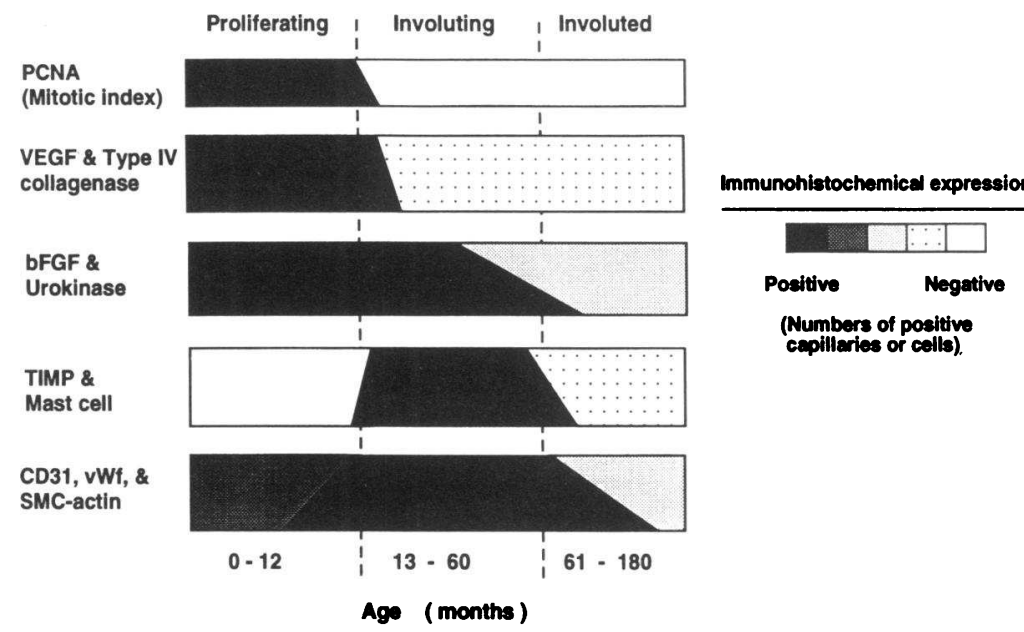

Figure 5. Summary of hemangioma's growth cycle. PCNA, VEGF, and type IV collagenase were detected in the proliferating phase, but not in the involuting phase lesions. In contrast, TIMP staining and mast cells manifested during the involuting phase. The other markers like bFGF and urokinase and the phenotypic markers, CD31, vWf, and SMC-actin, were present in sections from both the proliferative and involuting phase lesions.

both the involuting and the involuted phases. This antigen is a marker for differentiated smooth muscle cells known to inhibit endothelial cell proliferation in vitro $(48,49)$.

Our goal is to understand the pathophysiology of hemangiogenesis and regression. A pattern of events may be inferred from findings of this initial study (Fig. 5). In the third trimester, immature endothelial cells that are CD31 and vWf negative coexist with immature pericytes. These cells maintain an embryonic proliferative capacity pre- and postnatal life. Rapid clinical growth, observed biochemically by PCNA expression, is mediated, in part, by angiogenic peptides VEGF and bFGF. It can be envisioned that proteolysis with type IV collagenase and later urokinase may be needed to provide space for the proliferating capillary network (see Fig. 3). Angiogenic peptides may act to induce differentiation of proliferative cells in the hemangioma. The differentiating cells signal an influx of mast cells and autocrine induction of TIMP 1 expression, thus changing the growth pattern and initiating involution. TIMP 1 is well recognized for its role as an inhibitor of endothelial invasion into yolk sac membrane and as a negative regulator of angiogenesis, presumably by inhibition of angiogenic proteases like type IV collagenase and urokinase $(17,18)$. Mast cells may secrete modulators that downregulate hemangiogenesis, for example interferons and transforming growth factors (50-52). Thus, the lesion differentiates, with senescence of endothelial cells and with fibrosis and fat formation.

The results described in this report provide an objective basis for staging hemangioma. It is possible that expression of these markers may play a role in regulating the growth and regression of this tumor. Of note is that the staining pattern of vascular malformations was similar to that observed in involuted hemangioma ( Table II). These results confirm that vascular malformations do not consist of actively proliferating blood vessels. The effect of corticosteroids (53-55) and interferon alfa-2a (56-59) on the pattern of expression of this cohort of markers may provide insight into how these drugs accelerate involution of proliferating hemangiomas.

\section{Acknowledgments}

We thank Drs. Ira Herman, Donald Senger, Zena Werb, and William Stetler-Stevenson for providing anti-SMC-actin Ab, anti-VEGF $\mathrm{Ab}$,
anti-TIMP $\mathrm{mAb}$, and anti-type IV collagenase $\mathrm{mAb}$, respectively. We are also grateful to Takeda Chemical Co. for providing anti-bFGF antibody. We are also indebted to Bruce Ekstein and Jean Lai for expert confocal microscopic imaging and 3-D reconstitution. Helpful technical advice by Dr. Paul McNeil is also appreciated. We thank Marsha Kartzman for helping in the preparation of this manuscript.

Dr. Takahashi is supported by a Fellowship from Hoffmann-LaRoche (Nutley, NJ). Dr. Ezekowitz is an Established Investigator of the American Heart Association. This work is supported by National Institutes of Health grant MOIRR02172.

\section{References}

1. Pratt, G. A. 1953. Birthmarks in infants. Arch. Dermatol. 67:302-305.

2. Holmdahl, K. 1955. Cutaneous hemangiomas in premature and mature infants. Acta Paediatr. 44:370-379.

3. Amir, J., A. Metzker, R. Krikler, and S. H. Reisner. 1986. Strawberry hemangioma in preterm infants. Pediatric Dermatology. 3:131-132.

4. Bowers, R. E., E. A. Graham, and K. M. Tominson. 1960. The natural history of the strawberry nevus. Arch. Dermatol. 82:667-670.

5. Mulliken, J. B., and A. E. Young. 1988. Vascular Birthmarks: Hemangiomas and Malformations. W. B. Saunders Co., Philadelphia. 63-76.

6. Kasabach, H. H., and K. K. Merritt. 1940. Capillary hemangiomas with extensive purpura. Am. J. Dis. Child. 59:1063-1070.

7. Mulliken, J. B., and J. Glowacki. 1982. Hemangiomas and vascular malformations in infants and children: a classification based on endothelial characteristics. Plast. Reconstr. Surg. 69:412-420.

8. Mulliken, J. B., B. R. Zetter, and J. Folkman. 1982. In vitro characteristics of endothelium from hemangiomas and vascular malformations. Surgery (St. Louis). 92:348-353.

9. Folkman, J. 1974. Tumor angiogenesis. Adv. Cancer Res. 19:331-358.

10. Folkman, J., and R. Cotran. 1976. Relation of vascular proliferation to tumor growth. Int. Rev. Exp. Pathol. 16:207-248.

11. Risau, W., H. Sariola, H. G. Zerwes, J. Sasse, P. Ekblom, R. Kemler, and T. Doetschman. 1988. Vasculogenesis and angiogenesis in embryonic-stem-cellderived embryoid bodies. Development (Camb.). 102:471-478.

12. Folkman, J., and M. Klagsburn. 1987. Angiogenic factors. Science (Wash. DC). 235:442-447.

13. Zetter, B. R. 1988. Angiogenesis. State of the art. Chest. 93(Suppl. 3):159S-166S

14. Breier, G., U. Albrecht, S. Sterrer, and W. Risau. 1992. Expression of vascular endothelial growth factor during embryonic angiogenesis and endothelial cell differentiation. Development (Camb.). 114:521-532.

15. Pepper, M. S., N. Ferrara, L. Orci, and R. Montesano, 1992. Potent synergism between vascular endothelial growth factor and basic fibroblast growth factor in the induction of angiogenesis in vitro. Biochem. Biophys. Res. Commun. 189:824-831.

16. Montesano, R., J. D. Vassalli, A. Baird, R. Guillemin, and L. Orci. 1986. Basic fibroblast growth factor induces angiogenesis in vitro. Proc. Natl. Acad. Sci. USA. 83:7297-7301.

17. Mignatti, P., R. Tsuboi, E. Robbins, and D. B. Rifkin. 1989. In vitro angiogenesis on the human amniotic membrane: requirement for basic fibroblas growth factor-induced proteinases. J. Cell Biol. 108:671-682. 
18. Takigawa, M., Y. Nishida, F. Suzuki, J. Kishi, K. Yamashita, and T. Hayakawa. 1990. Induction of angiogenesis in chick yolk-sac membrane by polyamines and its inhibition by tissue inhibitors of metalloproteinases (TIMP and TIMP-2). Biochem. Biophys. Res. Commun. 171:1264-1271.

19. Pasyk, K. A., W. C. Grabb, and G. W. Cherry. 1983. Crystalloid inclusions in endothelial cells of cellular and capillary hemangiomas. A possible sign of cellular immaturity. Arch. Dermatol. 119:134-137.

20. Pasyk, K. A., W. C. Grabb, and G. W. Cherry. 1982. Cellular haemangioma. Light and electron microscopic studies of two cases. Virchows Arch. A. Pathol. Anat. 396:103-126.

21. Yasunaga, C., K. Sueishi, H. Ohgami, S. Suita, and T. Kawanami. 1989. Heterogenous expression of endothelial cell markers in infantile hemangioendothelioma. Immunohistochemical study of two solitary cases and one multiple one. Am. J. Clin. Pathol. 91:673-681.

22. Glowacki, J., and J. B. Mulliken. 1982. Mast cells in hemangiomas and vascular malformations. Pediatrics. 70:48-51.

23. Pasyk, K. A., G. W. Cherry, W. C. Grabb, and G. H. Sasaki. 1984. Quantitative evaluation of mast cells in cellularly dynamic and adynamic vascular malformations. Plast. Reconstr. Surg. 73:69-77.

24. Dethlefsen, S. M., J. B. Mulliken, and J. Glowacki. 1986. An ultrastructural study of mast cell interactions in hemangiomas. Ultrastruct. Pathol. 10:175183.

25. Gonzalez-Crussi, F., and M. Reyes-Mugica. 1991. Cellular hemangiomas ("hemangioendotheliomas") in infants. Light microscopic, immunohistochemical, and ultrastructural observations. Am. J. Surg. Pathol. 15:769-778.

26. Nichols, G. E., M. J. Gaffey, S. E. Mills, and L. M. Weiss. 1992. Lobular steroid hormone receptor status. Am. J. Clin. Pathol. 97:770-775.

27. Burgdorf, W. H., K. Mukai, and J. Rosai. 1981. Immunohistochemical identification of factor VIII-related antigen in endothelial cells of cutaneous lesions of alleged vascular nature. Am. J. Clin. Pathol. 75:167-171.

28. Bolton, W. E., W. R. Mikulka, C. G. Healy, R. J. Schmittling, and N. S. Kenyon. 1992. Expression of proliferation associated antigens in the cell cycle of synchronized mammalian cells. Cytometry. 13:117-126.

29. Rogers, R. A., E. H. Oldmixon, and J. D. Brain. 1992. Enhanced contrast within plastic imbedded tissue by Lucifer yellow-CH. An ideal stain for laser scanning confocal microscopy. Mol. Biol. Cell. 3(Suppl.):185a. (Abstr.).

30. Waseem, N. H., and D. P. Lane. 1990. Monoclonal antibody analysis of the proliferating cell nuclear antigen (PCNA). Structural conservation and the detection of a nucleolar form. J. Cell Sci. 96:121-129.

31. Kuzu, I., R. Bicknell, A. L. Harris, M. Jones, K. C. Gatter, and D. Y. Mason. 1992. Heterogeneity of vascular endothelial cells with relevance to diagnosis of vascular tumours. J. Clin. Pathol. 45:143-148.

32. Naiem, M., J. Gerdes, Z. Abdulaziz, C. A. Sunderland, M. J. Allington, H. Stein, and D. Y. Mason. 1982. The value of immunohistological screening in the production of monoclonal antibodies. J. Immunol. Methods. 50:145-160.

33. Seno, M., M. Iwane, R. Sasada, N. Moriya, T. Kurokawa, and K. Igarashi. 1989. Monoclonal antibodies against human basic fibroblast growth factor. $\mathrm{Hy}$ bridoma. 8:209-221.

34. Senger, D. R., D. T. Connolly, L. Van De Water, J. Feder, and H. F. Dvorak. 1990. Purification and NH2-terminal amino acid sequence of guinea pig tumor-secreted vascular permeability factor. Cancer Res. 50:1774-1778.

35. Dvorak, H. F., T. M. Sioussat, L. F. Brown, B. Berse, J. A. Nagy, A. Sotrel, E. J. Manseau, L. Van De Water, and D. R. Senger. 1991. Distribution of vascular permeability factor (vascular endothelial growth factor) in tumors: concentration in tumor blood vessels. J. Exp. Med. 174:1275-1278.

36. Monteagudo, C., M. J. Merino, J. San-Juan, L. A. Liotta, and W. G. Stetler-Stevenson. 1990. Immunohistochemical distribution of type IV collagenase in normal, benign, and malignant breast tissue. Am. J. Pathol. 136:585-592.

37. Sier, C. F., C. Fellbaum, H. W. Verspaget, M. Schmitt, G. Griffioen, H. Graeff, H. Hofler, and C. B. Lamers. 1991. Immunolocalization of urokinasetype plasminogen activator in adenomas and carcinomas of the colorectum. Histopathology (Oxf.). 19:231-237.
38. Herman, I. M., and P. A. D'Amore. 1985. Microvascular pericytes contain muscle and nonmuscle actins. J. Cell Biol. 101:43-52.

39. Weidner, N., J. P. Semple, W. R. Welch, and J. Folkman. 1991. Tumor angiogenesis and metastasis-correlation in invasive breast carcinoma. $N$. Engl. J. Med. 324:1-8.

40. Gospodarowicz, D., J. A. Abraham, and J. Schilling. 1989. Isolation and characterization of a vascular endothelial cell mitogen produced by pituitary-derived folliculo stellate cells. Proc. Natl. Acad. Sci. USA. 86:7311-7315.

41. Jakeman, L. B., J. Winer, G. L. Bennett, C. A. Altar, and N. Ferrara. 1992. Binding sites for vascular endothelial growth factor are localized on endothelial cells in adult rat tissues. J. Clin. Invest. 89:244-253.

42. Dvorak, H. F., J. A. Nagy, J. T. Dvorak, and A. M. Dvorak. 1988. Identification and characterization of the blood vessels of solid tumors that are leaky to circulating macromolecules. Am. J. Pathol. 133:95-109.

43. Muthukrishnan, L., E. Warder, and P. L. McNeil. 1991. Basic fibroblast growth factor is efficiently released from a cytolsolic storage site through plasma membrane disruptions of endothelial cells. J. Cell. Physiol. 148:1-16.

44. Schulze-Osthoff, K., W. Risau, E. Vollmer, and C. Sorg. 1990. In situ detection of basic fibroblast growth factor by highly specific antibodies. Am. J. Pathol. 137:85-92.

45. Folkman, J., M. Klagsbrun, J. Sasse, M. Wadzinski, D. Ingber, and I. Vlodavsky. 1988. A heparin-binding angiogenic protein-basic fibroblast growth factor-is stored within basement membrane. Am. J. Pathol. 130:393-400.

46. Sunderkotter, C., J. Roth, and C. Sorg. 1990. Immunohistochemical detection of bFGF and TNF- $\alpha$ in the course of inflammatory angiogenesis in the mouse cornea. Am. J. Pathol. 137:511-515.

47. Folkman, J., S. Szabo, M. Stovroff, P. McNeil, W. Li, and Y. Shing. 1991. Duodenal ulcer. Discovery of a new mechanism and development of angiogenic therapy that accelerates healing. Ann. Surg. 214:414-425; Discussion 426-427.

48. Glukhova, M. A., M. G. Frid, and V. E. Koteliansky. 1990. Developmental changes in expression of contractile and cytoskeletal proteins in human aortic smooth muscle. J. Biol. Chem. 265:13042-13046.

49. Glukhova, M. A., M. G. Frid, and V. E. Koteliansky. 1991. Phenotypic changes of human aortic smooth muscle cells during development and in the adult vessel. Am. J. Physiol. 261 (Suppl. 4):78-80.

50. Antonelli-Orlidge, A., K. B. Saunders, S. R. Smith, and P. A. D'Amore. 1989. An activated form of transforming growth factor beta is produced by cocultures of endothelial cells and pericytes. Proc. Natl. Acad. Sci. USA. 86:45444548.

51. Gordon, J. R., P. R. Burd, and S. J. Galli. 1990. Mast cells as a source of multifunctional cytokines. Immunol. Today. 11:458-464.

52. Friesel, R., A. Komoriya, and T. Maciag. 1987. Inhibition of endothelial cell proliferation by gamma-interferon. J. Cell Biol. 104:689-696.

53. Bartoshesky, L. E., M. Bull, and M. Feingold. 1978. Corticosteroid treatment of cutaneous hemangiomas: how effective? A report on 24 children. Clin. Pediatr. (Phila.). 17:625, 629-638.

54. Kushner, B. J. 1985. The treatment of periorbital infantile hemangioma with intralesional corticosteroid. Plast. Reconstr. Surg. 76:517-526.

55. Sloan, G. M., J. F. Reinisch, L. S. Nichter, W. L. Saber, K. Lew, and D. T. Morwood. 1989. Intralesional corticosteroid therapy for infantile hemangiomas. Plast. Reconstr. Surg. 83:459-467.

56. White, C. W., H. M. Sondheimer, E. C. Crouch, H. Wilson, and L. L. Fan. 1989. Treatment of pulmonary hemangiomatosis with recombinant interferon alfa-2a. N. Engl. J. Med. 320:1197-1200.

57. Orchard, P. J., C. M. Smith III, W. G. Woods, D. L. Day, L. P. Dehner, R. Shapiro, and C. M. Smith. 1989. Treatment of haemangioendotheliomas with alpha interferon. Lancet. 2(8662):565-567.

58. White, C. W., S. J. Wolf, D. N. Korones, H. M. Sondheimer, M. F. Tosi, and A. Yu. 1991. Treatment of childhood angiomatous diseases with recombinant interferon alfa-2a. J. Pediatr. 118:59-66.

59. Ezekowitz, R. A., J. B. Mulliken, and J. Folkman. 1992. Interferon alfa-2a therapy for life-threatening hemangiomas of infancy. N. Engl. J. Med. 326:14561463. 